\title{
Suicide reporting in the Swiss print media
}

\author{
Frequency, form and content of articles
}

\author{
KONRAD MICHEL, CONRAD FREY, THOMAS E. SCHLAEPFER, LADISLAV VALACH *
}

\begin{abstract}
All the Swiss newspapers were screened for the target words 'suicide' and 'attempted suicide' and all relevant articles were analysed for form and content over a period of 8 months. In 151 out of 208 articles suldde/attempted suicide was the major topic. Large differences between the newspapers regarding the frequency and format of the articles (e.g. placement on front page) were found. In a few newspapers with a large circulation sulcide is clearly treated as a major topic of news sensation. The majority of articles reported cases of completed suicide, mainly shooting and hanging by young persons. Attempted suicide was only reported for persons with celebrity status. This survey shows that there is reason for concern in view of the danger of imitation effects.
\end{abstract}

Key words: suicide, attempted suicide, prevention, print media

O uicide as a topic in the media has become a public health issue after several reports indicated that there is an association between media reporting about suicides and suicidal behaviour in a society. Sonneck et al. ${ }^{2}$ showed that after Austrian newspaper editors had been given guidelines for more cautious covering of suicides the number of suicides in the Viennese Metro (above all, young persons throwing themselves in front of trains) consequently dropped by more than $70 \%$ and remained low during the following years. Earlier, Motto ${ }^{3}$ and Blumenthal and Bergner ${ }^{4}$ had found some evidence for imitative suicidal behaviour related to the availability of newspapers. Other authors found an increase in suicides after publication or television broadcasting of suicide stories. ${ }^{5-8}$ Fekete and Macsai ${ }^{9}$ reported a dramatic increase of suicides with Lidocain after the widely published suicide of a beauty queen with this drug.

In order to be able to influence the reporting about suicide we felt that the actual way this topic is covered in printed media should first be monitored. To our knowledge there are so far no systematic investigations into the importance of suicide and attempted suicide as a topic in the media. In the first part of our investigation we specifically wanted to know how often this subject appears in newspapers, how much weight it is given and what kind of picture of the suicidal person or the act itself is presented to the reader. It should be noted that in Switzerland no guide-

This study is part of the suicide prevention programme of the Swiss Medical Association and the Swiss Federal Office of Health.'

\footnotetext{
* K. Michel, L Valach, Outpatients Department of Psychiatry, University of Berne, Switzerland

C Frey, Psychosomatic Unit, Pediatric Division, University of Berne, Switzerland

T.E. Schlaepfer, now Johns Hopkins Department of Psychiatry and Behavior al Sciences, Battimore, USA

Correspondence: Or. K. Mikhel, Psychistrische UnivershtStspollklinik Murtenstrasse 21, CH-3010 Bern, Switzerland, tet +41316328811. fax +41313811331
}

lines for suicide reporting have been issued. Our assumptions were that reporting of suicide and attempted suicide varies considerably according to the character of the newspaper, that some papers use this topic as news sensation and that the picture of suicidal behaviour that newspaper readers are given does not reflect reality.

\section{METHOD}

Over a time span of 8 months (April - November 1991) all daily, weekly and monthly papers pronted in Switzerland (exclusive of medical and other specialized journals) in German, French and Italian were screened by a professional media monitoring service ('Argus der Presse') for texts including words such as suicide and attempted suicide. Altogether some 400 newspapers and magazines were examined. The collected newspaper clippings were carefully read by the authors and coded for statistical analysis. The descriptive statistics and chi-squared calculation was performed with SPSS-X. ${ }^{10}$ Coding included the format of the articles as well as their content and consisted of 54 variables. Reports issued by press agencies which were published unchanged were counted as 1 article (press agency reports on suicide, however, were very rare).

Altogether 223 newspaper clippings were collected, carefully read and coded. Fifteen of these, such as letters to the editor, film reviews, deaths which were not suicides, etc., were excluded, leaving a total of 208 articles for analysis.

\section{Reliability of data collection}

The media monitoring office maintains from their own investigations that on average $85 \%$ of all articles in which a target word is present are recognized. We can assume that missed articles mainly concern articles where suicide and attempted suicide were not major key words and were therefore difficult to spot. Such articles are unlikely to have much impact on the reader. 


\section{Reliability of rating}

In 19 randomly selected articles ( $9 \%$ of the total) the complete rating was done independently by C.F. and K.M. Differences in rating were found in $48(7.4 \%)$ of the 646 variables.

\section{RESULTS}

Articles ( $n=208$ )

In the 8 months of monitoring, 74 newspapers and magazines were found to include articles with at least 1 of the target words. Of these papers $80.3 \%$ appear daily, $14.9 \%$ weekly and $4.8 \%$ less frequently. In 32 publications more than 1 article was found, the maximum being 35 articles in 8 months. Over half of all articles appeared in the same 10 newspapers (see table 1 ).

The distribution over the 8 months (April - November) was very uneven: while over half of the articles (107) appeared from April to June, in the autumn months (September - November) only 42 articles (20.2\%) were found. It should be noted that the figures cannot be a measure of the numbers of suicides occurring; the fluctuation is due mainly to a few events of special interest being widely reported.

Switzerland has 3 main languages, German representing $63.6 \%$ of the population, French $19.2 \%$ and Italian $7.6 \%$. The distribution of the articles by language was as follows: 76.0\% German, 17.8\% French and 5.8\% Iralian. This indicates that the relative number of articles was higher in the publications in the German language and lower in the others.

Table 1 shows the distribution of the main newspapers by the number of articles. The 2 newspapers with the highest numbers of articles are both German Swiss, followed by 2 French Swiss newspapers. The 2 German Swiss newspa-

Table 1 Circulation figures of selected Swiss newspapers and numbers of articles with the target words (suicide/attempted suicide) found in 8 months' monitoring

\begin{tabular}{lccc}
\hline & Circulation & $\begin{array}{c}\text { Number of } \\
\text { articles }\end{array}$ & $\begin{array}{c}\text { \% of all } \\
\text { articles }\end{array}$ \\
\hline Blick & 364,700 & 35 & 16.8 \\
Tages-Anzeiger Zürich & 261,369 & 23 & 11.1 \\
La Suisse & 70,032 & 13 & 6.3 \\
Le Matin & 53,774 & 11 & 5.3 \\
Die Wochenzeitung ${ }^{\text {a }}$ & 18,500 & 9 & 4.3 \\
Cornere del Ticino & 35,225 & 7 & 3.4 \\
L'Impartial $_{\text {Solothurner Zeinung }}$ & 31,072 & 4 & 1.9 \\
Der Landbote & 45,542 & 4 & 1.9 \\
Der Schweiz. Beobachter ${ }^{\text {b }}$ & 40,775 & 3 & 1.4 \\
Other newspapers with & 407,669 & 4 & 1.9 \\
circulation figures $>100,000$ & & & \\
$\quad$ Neue Zürcher Zeitung & 151,660 & 3 & 1.4 \\
Basler Zeitung & 113,421 & 3 & 1.4 \\
Berner Zeitung & 124,130 & 1 & 0.5 \\
Sonntags Blick & 350,380 & 3 & 1.4 \\
Die Weltwoche & 109,369 & 1 & 0.5 \\
\hline a Weekly & & & \\
b Monthly & & & \\
\hline
\end{tabular}

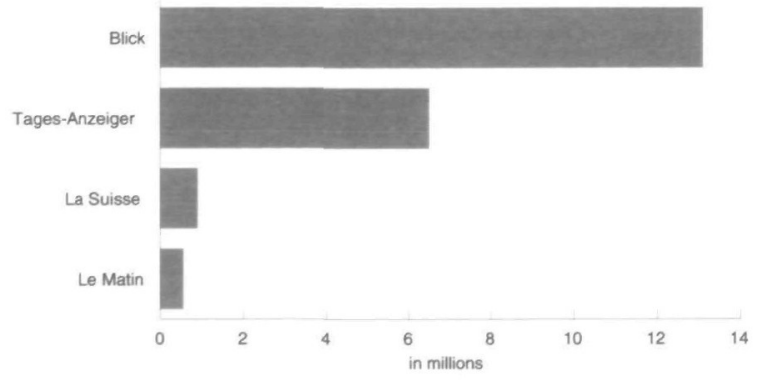

Figure A hypothetical index for the impact of suicide reporting (number of articles in 8 months $\times$ circulation of newspaper) for the 4 newspapers with most frequent suicide coverage

pers most frequently reporting about suicide happen to be the 2 daily papers with the highest circulation figures, but this is not the case for French Swiss publications, where the topic is hardly covered by the 3 newspapers with the largest circulation. None of the Italian Swiss papers had frequent coverage. To gain a picture of the assumed impact of the suicide reporting by the most frequently reporting papers the number of articles were multiplied by the circulation figures (see figure).

Obviously, in certain cases the same event resulted in articles in several papers. Those events with the highest number of articles were as follows. i) The death of a man aged 24 years, who, being armed, had called the police threatening to shoot himself but who started to fire at the police and who, after a fire exchange, died by his own gun (14 articles). ii) A popular actress and writer, taking an overdose ( 10 articles). iii) A customs official who killed himself after having shot two of his colleagues ( 6 articles).

\section{Form of presentation ( $n=151$ key word articles)}

In 151 articles (72.6\%) suicide or attempted suicide was the main or one of the main key words. The length of these articles varied from 5 to 380 lines, with a median of 55 lines. The longest articles covered overdoses taken by celebrities. A picrure accompanied 59 articles (39.1\%), of which 13 (22\%) appeared on the front page. Details of the method used for suicide were shown in 8 pictures and details of the location in 20 pictures.

The article or the headline appeared on the front page in 22 articles (14.6\%). This is a conservative figure, as in a few cases it was not possible to determine with certainty if the newspaper clip was taken from the front page. However, the main tabloid in German clearly had 15 articles alone on the front page. A target word was found in the headline of 94 articles (62.3\%). In 74 cases (49.0\%) the headline print was rated as oversized, mainly in cases of shooting and hanging ( 46 articles).

Character of articles $(n=151)$

The articles were grouped according to their character. news only (see appendix for examples) 45 (29.8\%), news with background information 52 (34.4\%), background information only (see appendix for examples) 35 (23.2\%), columns $6(4.0 \%)$, obituaries $4(2.6 \%)$, other $9(5.9 \%)$. 
People included ( $n=139$ people articles)

In 139 of the 208 articles details of the person included were given. One hundred and two of these $(73.4 \%)$ were male and $37(26.6 \%)$ were female. Ninery men (88.2\%) had completed suicide while only 13 women (35.\%) had done so $\left(\chi^{2}=37.15\right.$, $\left.p<0.0001\right)$. One hundred and four persons (74.8\%) were Swiss.

In 86 articles (61.9\%) the person was a non-celebrity, in 30 cases $(21.6 \%)$ the person was an international celebrity and in 23 cases (16.5\%) a local celebrity. Table 2 shows some of the differences between articles about celebrities (C) and non-celebrities ( $\mathrm{nC}$ ).

One hundred and three articles (74.1\%) referred to cases of completed suicide and the rest referred to attempted suicide. In 104 (74.8\%) of the articles about people the method used for the suicidal act was mentioned: shooting ( 52 cases, 37.4\%) was most frequent, followed by hanging (12 cases, $8.6 \%$ ), overdosing ( 15 cases, $11.1 \%$ ), jumping (12 cases, $8.6 \%$ ), and gassing ( 6 cases, $4.3 \%$ ). Shooting and jumping were associated with non-celebrity status and overdosing with celebrity status $\left(\chi^{2}=20.32, \mathrm{~d} f=4\right.$, $\mathrm{p}<0.001$ ).

A reason for the suicidal act was specified in 74 articles (53.2\%). Depression (25.7\%) and relationship problems (25.7\%) were the main reasons given, followed by personal and health problems $(17.6 \%)$, work problems (14.9\%) and emotional crises (9.5\%).

In 88 articles the age of the person was mentioned. The age range was from 20 to 80 years, the median being 35 years. Twenty-one ( $23.9 \%$ ) were 25 years old or younger. Of these, the majority $(90.5 \%)$ were non-celebrities. Most of them shot $(52.6 \%)$ or hanged themselves $(21 \%)$ and none overdosed. The explanations given for the suicides of young persons mainly fell into the category 'crisis' (33.3\%), while for those above 25 years it was mainly relationship problems $(39.5 \%)$, personal and health problems (23.7\%) and depression (18.7\%).

Following the uneven distribution of the number of suicide reports in the different papers we were interested in whether the frequently reporting papers also differ in their dealing with suicide as a topic. We divided the 139 articles into 68 articles from the papers with frequent and 71 articles from papers with less frequent reporting of suicide. The first group of articles came from 4 and the second group from 67 papers. Table 3 shows the main differences

Table 2 Comparison of articles about non-celebrity persons with articles about celebrities

\begin{tabular}{lccrr}
\hline & \multicolumn{2}{c}{$\begin{array}{c}\text { Non-celebrittes } \\
\mathrm{n} \times 86\end{array}$} & \multicolumn{2}{c}{$\begin{array}{c}\text { Celebrities } \\
\mathrm{n}=53\end{array}$} \\
& $\mathrm{n}$ & \% & $\mathrm{n}$ & $\%$ \\
\hline Target word in headline & 45 & 52.3 & 18 & 34.0 \\
Context in headline & 26 & 30.2 & 4 & 7.5 \\
Method in text & 70 & 81.4 & 34 & 64.2 \\
Location of the act mentioned & 70 & 81.4 & 24 & 45.3 \\
'Fate' as explanation & 23 & 26.7 & 6 & 11.3 \\
Person is Swiss & 75 & 87.2 & 29 & 54.7 \\
\hline
\end{tabular}

Differences are all siginificant at a $5 \%$ level $\left(\chi^{2}\right.$ rest) between the 2 groups. It emerges that the coverage by the few 'frequent reporters' is characterized by news character, the headline and picture appearing on the front page and the suicide method being mentioned explicitly, especially shooting and hanging, even in the headlines.

\section{DISCUSSION}

Research into the impact of suicide reporting in the electronic and printed media indicates that news accounts of suicides can trigger additional suicides among susceptible persons. Stack ${ }^{11}$ argued that in this field a differential identification model is needed and he found evidence for an age-specific identification process, especially in young men. Furthermore, the report by Sonneck et al. ${ }^{2}$ makes it evident that changes in the policy of suicide reporting in newspapers can indeed reduce the frequency of suicides with a specific method, again, mainly in young persons. As Switzerland has one of the highest suicide rates among young men aged $15-24$ years ${ }^{12,13}$ we felt that suicide reporting in Swiss newspapers should be evaluated and, if necessary, guidelines for media coverage of suicide stories be issued. We believed that objective information on the press coverage of suicide and attempted suicide would not only help us to approach editors, but could also serve as a baseline against which the effect of issuing such guidelines could be measured.

A possible contagious effect of media reporting of suicide is likely to be dependent on quantitative as well as qualitative aspects. Under quantitative aspects we record the length of an article and its position in the newspaper, the size and the wording of the headline, inclusion of pictures, etc., as well as the frequency of reporting. Qualitative aspects refer to the contents of the reporting, above all the question of how much an article serves as a model to susceptible persons and how much weight is given to measures of prevention. In this paper we focus on the quantitative aspects.

Table 3 Comparison of artıcles from newspapers with frequent suicide reporting (more than 10 artıcles) with those from papers with infrequent suicide reporting

\begin{tabular}{lcrrr}
\hline & \multicolumn{2}{c}{$\begin{array}{c}\text { Frequent } \\
\text { reporting } \\
\text { n=68 }\end{array}$} & \multicolumn{2}{c}{$\begin{array}{c}\text { Infrequent } \\
\text { reporting } \\
\text { n=71 }\end{array}$} \\
& $\mathbf{n}$ & \multicolumn{1}{c}{$\%$} & $\mathrm{n}$ & $\%$ \\
\hline Length of article (>62 lines) & 24 & 33,8 & 40 & 58.8 \\
Headline on front page & 20 & 28.2 & 3 & 4.2 \\
Picture on front page & 20 & 18.3 & 2 & 2.9 \\
Headline large print & 48 & 67.6 & 22 & 32.4 \\
News character & 36 & 50.7 & 16 & 23.5 \\
Method named & 61 & 85.9 & 43 & 63.2 \\
Method in headline & 22 & 31.0 & 11 & 16.2 \\
Shooting as method & 36 & 50.7 & 3 & 4.2 \\
Circumstances described & 56 & 78.9 & 38 & 55.9 \\
Same case more than once & 17 & 23.9 & 6 & 8.8 \\
\hline
\end{tabular}

Differences are all significant at the $5 \%$ level ( $\chi^{2}$ test). No significant differences were found for the following variables: hanging as method, name of person mentioned and number of picaures 
Our results show that there are enormous differences in the frequency of articles between the various print media. For some newspapers suicide obviously is an important topic while others hardly ever cover it. It could be argued that, in general, suicide reports are rare as out of 400 print titles only 74 were found to carry articles with 1 of the target words. Such a conclusion would be wrong. Most of these 400 titles have a small circulation and are of very local character only, but, more important, the newspapers with frequent suicide reporting tend to be those with the highest circulation figures. The main German Swiss tabloid paper ('Blick') was found to cover the topic on average once a week. We can assume that in the Germanspeaking population the 2 main papers reach at least $35 \%$ of all households (population 4.4 million, 2.5 persons per household). It is not only the tabloids which frequently have suicide articles: the second paper frequently reporting suicide ('Tages-Anzeiger') can be considered a 'serious' newspaper. Obviously, the decision about how much weight should be given to suicide coverage must be made by the editors and we can only speculate as to what their motives are.

The fact that German Swiss newspapers include relatively more suicide articles than the newspapers in French and Italian Switzerland suggests that cultural differences may play a role.

Apart from the frequency of articles, we wanted to know in what way suicide and attempted suicide are covered. Our assumption was that the newspapers would differ in their character of suicide coverage, which was confirmed by our results. In the newspapers with frequent suicide reporting articles usually had news character and articles, headlines and pictures are often placed on the front page. Analysis of the content reveals that these papers have a preference for suicides through violent methods and for explicit description of the suicide methods and the circumstances of the act, even though the articles are generally shorter than those in newspapers with less frequent covering of the topic. It became therefore evident that certain papers indeed use suicide and attempted suicide as news sensation.

Suicide reporting obviously does not reflect reality. In newspapers attempted suicide is rare and completed suicide is frequent. The realiry is different: in Switzerland over 8,000 suicide attempts coming to medical attention are estimated per year ${ }^{14}$ and $\sim 1,500$ completed suicides are officially reported. The picture given is that the most common suicidal behaviour is shooting. In Switzerland shooting is indeed the main method in completed male suicides, but in the total of all suicides it represents only $28 \% 15$ and in attempted suicide $2 \%$ only. Overdoses, it appears from the newspapers, are the domain of persons with celebrity status and are not taken by young persons, a total contrast to reality (the highest rates for attempted suicide are in the age group 15-34 years ${ }^{14}$ ). The most disturbing finding is that the persons reported to have killed themselves by shooting or hanging are usually young and very average persons, i.e. persons with whom most young readers can easily identify. The reports by
Schmidtke and Häfner ${ }^{8}$, Sonneck et al. ${ }^{2}$ and Fekete and Macsai ${ }^{9}$ suggest that there is an age- and gender-specific imitation effect, especially in adolescents and young adults. Fekete and Macsai's ${ }^{9}$ paper is especially interesting because after the publicized suicide of a 17 year old beauty queen with Lidocain pills the number of female suicides in Hungary in the age group 15-39 years rose dramatically. We know little about the identification processes of young persons. Stack's ${ }^{11}$ results contradicted those of Wasserman ${ }^{16}$ who found an association between the presence of a celebrity suicide story and the monthly rate of suicides (all ages). Stack's ${ }^{11}$ differential identification showed that the non-celebrity status of the person who committed suicide was of similar importance and that identification seemed to work upwards and laterally, especially in the young and in the elderly, but not in the middle aged. However, for young males, he found that the greater the coverage of non-celebrity suicides, the greater the suicide rate was.

It seems obvious that suicides of public persons and suicides occurring in public places need to be reported and may even demand a prominent place in the newspapers. In our view, however, there is no justification for prominent covering of the suicides of private persons occurring in private places. Every suicide is a private affair. The reasons for putting an end to one's life are as varied as individuals can be. Half of the articles on persons gave some sort of explanation for the suicide act. Here, at least, there is some compatibility with reality, depression (the number 1 risk factor) being in the first place, followed by relationship and personal problems (which indeed are often found to be causes of suicidal behaviour). However, there is a tendency to over-simplify. When a headline runs 'Rows in the family: Boy (12) hanged himself ('Blick', 28 January 1994), it is obvious that this can serve as a model to children with family problems.

We can understand that journalists and editors are not aware of the possible impact of this form of presentation. Professional knowledge and guidelines must be circulated to newspaper editors. Editorial staff and journalists must be aware of the potential risk of suicide reporting and should be encouraged to contact designated experts on suicide prevention when uncertain about the way to present such a sensitive topic. Obviously, the right to information must be weighed against the risk of imitation. It seems to us that more interdisciplinary communication is needed and that a joint working group of health experts and journalists might prove useful. There is a considerable public health interest involved.

The professional screening of the newspapers was made possible by the financial support of the Swiss Medical Association.

The authors thank Mrs Barbara Weil for assistance in data analysis.

\section{REFERENCES}

1 Frey C. Michel K. Suizidverhatung. Projektunterlagen einer Aktion der Verbindung der Schweizer Aerzte und des Bundesamtes fūr Gesundheitswesen. Soz Prăventivmed 1991;36:346-50. 
2 Sonneck G, Nagel-Kuess S, Etzersdorfer E, Smeh E, Hauer B. Subway sucide in Vienna: a contribution to the imitation effect in suicidal behaviour 1984-1988. In: Ferrari G, Bellini M, Crepet P, editors. Suicidal behavior and risk factors. Bologna: Monduzzi Editore, 1990:77-82.

3 Motto JA: Newspaper influence on suicide. Arch Gen Psychiat 1970;23:143-8.

4 Blumenthal S, Bergner L. Suicide and newspapers: a replicated study. Am J Psychiat 1973;130:468-71.

5 Phillips DP. The influence of suggestion on suicide: substantive and theoretical implications of the Werther effect. Am Soc Rev 1974;39:340-54.

6 Bollen KA, Phillips DP. Imitative suicides: a national study of the effects of television news stories. Am Sociol Rev 1982;47:802-9.

7 Phillips DP, Carstensen LL. Clustering of teenage suicides after television news stories about suicide. $N$ Engl J Med 1986;315:685-9.

8 Schmidtke A, Hafner $H$. The Werther effect after television films: new evidence for an old hypothesis. Psychol Med 1988; 18:665-76.

9 Fekete $S$, Macsai E. Hungarian suicidal models: past and present. In: Ferrari G, Bellini M, Crepet P, editors. Suicidal

\section{Appendix}

i) Example of article with news character (translations by the authors), 'Suicide in the prison cell'. In a cell of the remand prison in Aarau a 37 year old Dutch woman hanged herself with her belt on Sacurday night. The woman had been arrested on Sarurday crossing the border at Koblenz after $7.1 \mathrm{~kg}$ of hashish with a value of 35,000 francs had been found ('Tages-Anzeiger', Zürich, daily, circulation 261,369, 3 June 1991).

ii) Example of article with background information, 'Medical doctors should be aware of suicide risk'. Doctors should be more attentive towards possible surcide risks of their patients. In 1992 the Swiss Medical Association (FMH) and the Federal Health Office (BAG) plan to start a prevention campaign primarily directed towards practicing physicians. Approximately $80 \%$ of persons who take their own lives were undergoing some form of medical trearment before the event. The number of suicides in the latest year with complete figures (1989) given by the Federal Statistical Office is 1,513 ('Bote der Urschweiz', 3 times per week, circulation 14,516, 21 May 1991). behavior and risk factors. Bologna: Monduzzi Editore, 1990:149-55.

10 SPSS Inc. SPSS-X user's guide. Chicago: SPSS Inc., 1988.

11 Stack S. Social correlates of suicide by age. Media impacts. In: Leenars AA, editor. Life span perspectives of suicide. New York: Plenum Press, 1991:187-213.

12 Lester D. Suicide across the life span. A look at

international trends. In: Leenars AA, editor. Life span perspectives of suicide. New York: Plenum Press, 1991:71-80.

13 Michaud PA. Jugendalter. In: Weiss W, editor. Gesund heit in der Schweiz. Zürich: Bundesamt für Gesundheitswesen, Seismo-Verlag, 1993:123-33.

14 Michel, K, Knecht Ch, Kohler I, Sturzenegger $M$. Suizidversuche in der Agglomeration Bern. Schweiz Med Wochenschr 1991;121:1133-9.

15 BFS, Bundesamt für Statistik. Bern: Sektion Gesundheit, 1992.

16 Wasserman I. Imitation and suicide: a reexamination of the Werther effect. Am Soc Rev 1984;49:427-36.

Received 16 March 1994, accepted 17 November 1994 